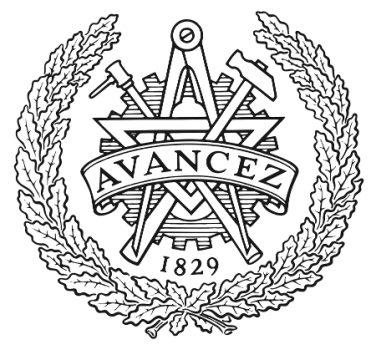

CHALMERS

UNIVERSITY OF TECHNOLOGY

\title{
Thermal and diffusion induced stresses in a structural battery under galvanostatic cycling
}

Downloaded from: https://research.chalmers.se, 2023-04-26 12:43 UTC

Citation for the original published paper (version of record):

Carlstedt, D., Asp, L. (2019). Thermal and diffusion induced stresses in a structural battery under galvanostatic cycling. Composites Science and Technology, 179: 69-78.

http://dx.doi.org/10.1016/j.compscitech.2019.04.024

N.B. When citing this work, cite the original published paper. 


\section{Accepted Manuscript}

Thermal and diffusion induced stresses in a structural battery under galvanostatic cycling

David Carlstedt, Leif E. Asp

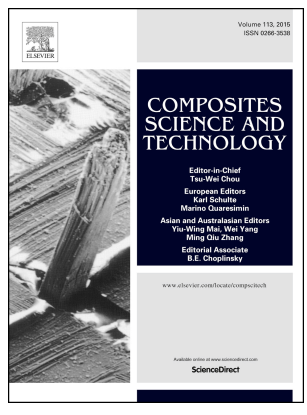

PII:

S0266-3538(19)30517-2

DOI: https://doi.org/10.1016/j.compscitech.2019.04.024

Reference: CSTE 7632

To appear in: Composites Science and Technology

Received Date: 22 February 2019

Revised Date: 16 April 2019

Accepted Date: 17 April 2019

Please cite this article as: Carlstedt D, Asp LE, Thermal and diffusion induced stresses in a structural battery under galvanostatic cycling, Composites Science and Technology (2019), doi: https:// doi.org/10.1016/j.compscitech.2019.04.024.

This is a PDF file of an unedited manuscript that has been accepted for publication. As a service to our customers we are providing this early version of the manuscript. The manuscript will undergo copyediting, typesetting, and review of the resulting proof before it is published in its final form. Please note that during the production process errors may be discovered which could affect the content, and all legal disclaimers that apply to the journal pertain. 


\title{
Thermal and diffusion induced stresses in a structural battery under galvanostatic cycling
}

\author{
David Carlstedt ${ }^{1}$, Leif E. Asp ${ }^{1 *}$ \\ ${ }^{1}$ Department of Industrial and Materials Science, Chalmers University of Technology, SE- \\ 41296 Gothenburg, Sweden \\ * Corresponding author. E-mail: leif.asp@ chalmers.se
}

\section{Abstract:}

When charging or discharging a structural battery composite heat will be generated and the active electrode materials will expand or shrink, inducing internal stresses within the material. These stresses may cause mechanical and/or electrical failure. It is therefore crucial to be able to predict the stress state when evaluating the performance of the material. In this paper, a semi-analytical framework to predict the thermal and diffusion induced stresses in a structural battery under galvanostatic cycling is presented. The proposed model is a concentric cylinder (CC) model coupled with an axisymmetric diffusion model and a onedimensional heat generation model. The present study shows that the heat generated during electrochemical cycling must be accounted for when evaluating the internal stress state in structural battery composites. Furthermore, the results show that the charge/discharge current, lamina dimensions and residual stresses have significant effect on the internal stress state and effective properties of the composite lamina.

Keywords: A. Carbon fibres; A. Functional composites; B. Electrical properties;

B. Mechanical properties; C. Modelling 


\section{Introduction}

A structural battery composite is a multifunctional composite material with ability to carry mechanical load while storing electrical energy (i.e. work as a battery). This emerging material is made from carbon fibre reinforced polymer where the carbon fibres work as both mechanical reinforcement and active material in the battery cell. Previous studies have shown that carbon fibre provides high specific mechanical and electrical properties, which makes it ideal for multifunctional application $[1,2]$. The structural battery is often referred to as "massless" energy storage due to its inherent ability to store energy without adding parasitic weight. Thereby the material has the potential to offer significant mass and volume savings on a system level $[3,4]$ and significantly improve the performance of future electric vehicles and devices. Two ways to realise the structural battery have been proposed, the laminated and the three-dimensional (3D) battery architecture. The former was first proposed by Wetzel et al. [3,5] and later demonstrated by Ekstedt et al. [6] and Carlson [7] while the latter was developed by Asp and co-workers [7-9]. In the laminated battery each lamina has a separate function and works as electrode, separator, collector, etc. while in the 3D battery each fibre is coated with a thin polymer coating and works as an individual micro battery cell. In this work, the 3D battery architecture is studied to demonstrate the capabilities of the developed semi-analytical framework.

As for ordinary batteries, charging and discharging the structural battery will generate heat and cause the electrode materials to expand or shrink. This will generate internal stresses inside the material. High internal stresses may cause mechanical and/or electrical failure [10] and for this reason it is crucial to be able to predict the internal stress state generated during electrochemical cycling. Furthermore, it is critical to understand how charge/discharge current (often referred to as C-rate) and design parameters such as cell dimensions, properties of constituents, etc. affect the developed stresses. For example, the electrical and ion 
conductivity of the individual phases in the structural battery (electrodes, electrolyte/separator and current collectors) are lower compared to ordinary lithium ion battery counterparts. The electrical conductivity of carbon fibres [2] is about three orders of magnitude lower than for copper, commonly used for current collectors in ordinary lithium ion batteries. Furthermore, the ion conductivity of solid polymer electrolytes used in structural batteries has been reported in the range $10^{-4}-10^{-8} \mathrm{~S} / \mathrm{cm}[11,12]$ while the conductivity of ordinary liquid electrolytes often are in the range $10^{-2}-10^{-3} \mathrm{~S} / \mathrm{cm}[13]$. This means that the ohmic losses over a given area and distance will be significantly higher in the constituents of the structural battery compared with counterparts in ordinary lithium ion battery. Furthermore, the cell dimensions (related to the length of the current flow in the different phases) and charge/discharge current will have significant effect on the generated heat inside the material. The generated heat will affect the properties of the constituents and, in combination with volume change of constituents, internal stresses will build up inside the material during electrochemical cycling.

In previous work on diffusion-induced stresses in structural batteries, stresses caused by volume change of electrode materials have been studied without considering the thermal effects associated with electrochemical cycling. Pupurs et al. [14] studied the diffusioninduced stresses in carbon fibres due to lithium concentration gradients associated with electrochemical cycling. Xu et al. $[15,16]$ have developed a numerical framework using a Multiphysics FE-model to study how the internal stresses in 3D structural batteries are affected by volume change of constituents. Moreover, Dionisi et al. [17] developed an analytical model to predict deformations and stresses in laminated structural batteries due to volume change of the active materials. Several studies have though shown that the developed stresses in lithium ion batteries are highly dependent on generated heat and temperature inside the cell. For example, work done by Wu et al. [18] and Zhang et al. [19] on ordinary 
lithium ion batteries concluded that thermal and diffusion-induced stresses should be considered simultaneously and that the thermal effects are highly dependent on the properties of the components. To date a model to predict the internal stresses in structural batteries due to a combination of heat generation and volume change of electrode materials is lacking.

The objective of this paper is to study the internal stresses in a 3D structural battery composite caused by heat generation and volume change of constituents under galvanostatic cycling (constant current charge/discharge cycles). A semi-analytical framework has been developed to predict the internal stresses based on a concentric cylinder (CC) model [20,21]. In this work the model has been modified and extended to predict internal stresses due to changes in volume (linked to lithium concentration) and temperature in constituents during electrochemical cycling. The CC-model is coupled with an axisymmetric diffusion model describing the lithium concentration distribution inside the fibre. Furthermore, the temperature variation inside the material during operation is derived using a one-dimensional heat generation model based on thermal energy balance. The developed model is used to study how the internal stresses in a 3D structural battery are affected by C-rate, lamina dimensions and residual stresses. To validate the semi-analytical framework a finite element (FE) model is setup in the commercial FE software COMSOL. The assumptions and limitations of our semi-analytical framework are emphasized in the following.

(1) In the CC-model, perfect adhesion between cylinder phases are assumed and the concentric cylinder is free to expand. The material phases are assumed to be transversally isotropic or isotropic and the response is assumed to be linear elastic (small deformations). (2) The internal stresses are resolved at fibre level (microlevel). Lithium ion concentration gradients in electrode particles (nanolevel) are neglected. (3) Galvanostatic operation is assumed and the analysis is one-way. Hence, the developed model only studies how heat generation and volume expansion/shrinkage of constituents associated with electrochemical 
cycling affect the mechanical stresses. The mechanical stresses are assumed not to affect the electrochemical capacity and flow of current within the cell. This assumption is motivated by observations made by Jacques et al. [22] who found the electrochemical capacity of T800 carbon fibres to be unaffected by mechanical loading. (4) Generated heat inside the material due to electrochemical cycling is assumed to be dominated by the ohmic heat generation rate. Hence, reversible and reaction heat generation rates are neglected. (5) Mass transport limitations in the electrolyte are not accounted for (related to electrical performance). This should be accounted for when estimating the electrical performance during operation in future studies. (6) The diffusion coefficient of the fibre is assumed constant during electrochemical cycling. This assumption is made to simplify the analysis and to allow for superposition of load steps. This assumption has been used in other studies $[14,15]$.

\section{Materials and geometry}

In the $3 \mathrm{D}$ battery design concept, the carbon fibres are coated with a thin solid polymer electrolyte which works as a combined electrolyte and separator layer [23]. The surrounding polymer matrix is doped with positive electrode particles (e.g. $\mathrm{LiFePO}_{4}$ ) to make it work as positive electrode in the battery cell. The matrix is also doped with an electrically conducting material, e.g. carbon black (cb), to enable electrical conduction within the matrix. The benefit of using this design concept is the significantly reduced distance between electrodes [9]. The 3D battery cell and the link between the material constituents and battery cell components are illustrated in Fig. 1. The carbon fibres are assumed to be made of IMS65 unsized fibres and the polymer electrolyte coating is assumed to be made of the polymer system used by Leijonmark et al. [23]. The polymer matrix is assumed to be made of a bi-continuous polymer network developed by Ihrner et al. [11] reinforced with $\mathrm{LiFePO}_{4}$ and carbon black particles. In the current analysis a baseline configuration of the composite lamina is defined based on previous work done by the authors $[21,24]$. The volume fraction of fibres is 
assumed to be $V_{\mathrm{f}}=0.3$, thickness of coating $\delta_{\mathrm{c}}=0.5 \mu \mathrm{m}$ and a volume fraction of particles within the matrix of $V_{\mathrm{p}}^{*}=0.5$. The assumed configuration represents values for an electrochemically balanced cell.

\subsection{Current flow inside battery}

The current flow inside the battery cell during discharge is illustrated in Fig. 2. The current is assumed to be driven by electron transport in the fibres and ion transport in the polymer coating and the polymer matrix from the coating-matrix interface to the electrode particles. Furthermore, the current is assumed to be driven by electron transport from the positive electrode particles to the current collector on the positive side (aluminium foil) via carbon black particles distributed in the matrix. The current is finally driven by electron transport through the aluminium foil and external circuit back to the fibres completing the circuit. The assumed lengths of the individual paths for the current flow in the different phases are listed in Table 1. No lengths are defined for the external circuit and aluminium foil as the resistive losses in these phases are considered negligible compared with other contributions. It is assumed that the length of the current path in the carbon fibres is equal to half the length of the lamina $\left(L_{\text {lam }} / 2\right)$. This corresponds to the average distance for the current to travel along the fibres inside the cell in the fibre direction. Furthermore, the length of the ion transport inside the matrix is assumed to be half the distance between the radius of the fibre plus coating $\left(r_{\mathrm{c}}=r_{\mathrm{f}}+\delta_{\mathrm{c}}\right)$ and the equivalent cylinder radius for the concentric cylinder $\left(r_{\mathrm{m}}=\right.$ $\left.r_{\mathrm{f}} / \sqrt{V_{\mathrm{f}}}\right)$ defined by the volume fraction of fibres $\left(V_{\mathrm{f}}\right)$. The length for the electrons to travel via the carbon black particles inside the matrix is assumed to be half the thickness of the lamina. This corresponds to an average distance between each fibre and the aluminium foil. This assumption is based on the fact that the current needs to flow from each fibre to the foil and this distance will vary between 0 and $\delta_{\text {lam }}$. It should be noted that the volume fraction of carbon black particles in the matrix is assumed to be above the percolation threshold [25] and 
the electrons are assumed only to travel via carbon black particles in the particle reinforced matrix. For the baseline configuration the following lamina dimensions are assumed:

$L_{\text {lam }}=10 \mathrm{~cm}, \delta_{\text {lam }}=0.01 \mathrm{~cm}$ and $w_{\text {lam }}=2 \mathrm{~cm}$. These dimensions correspond to assumed sample sizes in previous work by the authors [24].

\subsection{Lithium concentration, temperature and $C$-rate dependent properties}

The properties of the constituents will depend on the lithium concentration $(\bar{C})$, temperature (T) and C-rate $\left(C_{\text {rate }}\right)$. It should be noted that the lithium concentrations in the active materials are normalized with respect to the corresponding saturated concentration $\bar{C}=C / C_{\text {sat }}$. These values are defined based on the electrochemical capacities (referring to the amount of energy a material can store) of the fibres and particles at $C_{\text {rate }}=0.08$. The change in concentration is defined going from discharged to fully charged state. The state of charge (SOC) refers to the amount of energy currently stored in the battery. For a fully charged battery SOC is equal to one while for a discharged battery SOC is equal to zero. Due to the potential mismatch in available capacities of the active electrode materials SOC $=1$ does not imply that the fibres are fully saturated with lithium at this state. During lithiation $\mathrm{FePO}_{4}$ is known to undergo phase transition [26]. In this study, such phase transition is not explicitly modelled. Instead, reported material volume and stiffness for different lithium concentration are considered, assuming that these are governed by the diffusion process.

The assumed properties of the constituents are presented in Table 2. In Table $2 v$ is Poisson's ratio, $\rho$ the density and $c_{p}$ the specific heat. It should be noted that the C-rate (defined as $\left.C_{\text {rate }}\right)$ refers to the time for charging/discharging the battery. For example, $C_{\text {rate }}=6$ corresponds to charging or discharging the battery in 1/6 hours or 10 minutes. For simplicity the $\mathrm{C}$-rate for charge and discharge are assumed to be equal. The electrochemical capacity $(\Gamma)$ of the active electrode materials are approximated based on experimental data $[27,28]$ and reads 
$\Gamma_{\mathrm{f}}\left(C_{\text {rate }}\right)=\Gamma_{\mathrm{f}}^{0}\left(0.510-0.194 \ln \left(C_{\text {rate }}\right)\right)$ for $C_{\text {rate }} \in[0.08 ; 6]$

$\Gamma_{\mathrm{p}}\left(C_{\text {rate }}\right)=\Gamma_{\mathrm{p}}^{0}\left(0.824-0.070 \ln \left(C_{\text {rate }}\right)\right)$ for $C_{\text {rate }} \in[0.08 ; 6]$

where $\Gamma_{\mathrm{f}}^{0}=0.36 \mathrm{Ah} / \mathrm{g}$ and $\Gamma_{\mathrm{p}}^{0}=0.16 \mathrm{Ah} / \mathrm{g}$ are the assumed reversible capacities at a C-rate of 0.08 for the fibres and particles, respectively. It should be noted that the approximations in Eqs. (1)-(2) are based on the reversible capacities (neglecting the first-cycle capacity losses). The moduli of the carbon fibre are approximated bases on experimental data $[29,30]$ as $E_{\mathrm{L}, \mathrm{f}}\left(\bar{C}_{\mathrm{f}}\right)=E_{\mathrm{L}, \mathrm{f}}^{0}\left(1-0.10 \bar{C}_{\mathrm{f}}\right) \quad$ for $\bar{C}_{\mathrm{f}} \in[0 ; 1]$

$E_{\mathrm{T}, \mathrm{f}}\left(\bar{C}_{\mathrm{f}}\right)=E_{\mathrm{T}, \mathrm{f}}^{0}\left(1+1.5 \bar{C}_{\mathrm{f}}\right)$ for $\bar{C}_{\mathrm{f}} \in[0 ; 1]$

where $E_{\mathrm{L}, \mathrm{f}}^{0}=2.9 \cdot 10^{5} \mathrm{MPa}$ and $E_{\mathrm{T}, \mathrm{f}}^{0}=0.10 \cdot 10^{5} \mathrm{MPa}$ are the assumed longitudinal and transverse elastic properties of the carbon fibre in virgin state $\left(\bar{C}_{\mathrm{f}}=0\right)$. It should be noted that the moduli depend on the lithium concentration and that the approximations are limited to the range $\bar{C}_{\mathrm{f}} \in[0 ; 1]$. The variation in the longitudinal modulus of the carbon fibres $\left(E_{\mathrm{L}, \mathrm{f}}\right)$ is based on measurements done by Jacques et al. [29]. To the authors' knowledge no data is available on the change in transverse modulus of carbon fibres due to lithiation. In this analysis we assume the graphite planes within the carbon fibre are arranged along the fibre direction. Hence, the change in transverse modulus is assumed to be equivalent to the change in the out-of-basal-plane stiffness of graphite reported by Qi et al. [30]. Furthermore, the relative variation of the transverse modulus is assumed equivalent to the variation of the longitudinal modulus. The temperature dependent Young's moduli of the polymer coating and matrix are approximated based on experimental data [11,31] and are defined as

$$
\begin{aligned}
& E_{\mathrm{c}}(T)=\left\{\begin{array}{c}
E_{\mathrm{c}}^{0}(1-0.0533(T-25)) \text { for } T \in[25 ; 40] \\
20 \text { for } T \in[40 ; 100]
\end{array}\right. \\
& E_{\mathrm{m}}(T)=E_{\mathrm{m}}^{0}(1-0.007(T-25)) \text { for } T \in[25 ; 100],
\end{aligned}
$$


where $E_{\mathrm{c}}^{0}=100 \mathrm{MPa}$ and $E_{\mathrm{m}}^{0}=550 \mathrm{MPa}$ are the Young's modulus at room temperature of the coating and matrix, respectively.

The coefficients of thermal expansion $\left(\alpha_{\mathrm{L}}\right.$ and $\left.\alpha_{\mathrm{T}}\right)$ for the fibres are based on experimental data [32] and for the polymer coating and matrix are expected to be in the same range as for ordinary vinyl ester polymers. For the $\mathrm{LiFePO}_{4}$ particles the thermal expansion is assumed to be equivalent to that of iron. The expansion coefficients due to change in lithium concentration for the carbon fibres $\left(\beta_{\mathrm{f}}\right)$ and the particles $\left(\beta_{\mathrm{p}}\right)$ are based on experimental data $[27,33]$. It should be noted that the expansion coefficients due to change in lithium concentration is defined according to the standard convention for hygroscopic expansion. This convention is used due to the resemblances in the physical phenomena and as no hygroscopic expansion will be present in this type of material (the battery cell needs to be protected against moisture). The stiffness of the $\mathrm{LiFePO}_{4}$ particles are assumed unaffected by change in lithium concentration. This assumption is motivated by the fact that the average Young's modulus of $\mathrm{LiFePO}_{4}$ has been found unaffected by lithium concentration [34]. The ion conductivities of the coating and matrix are approximated based on experimental data $[11,35]$ and reads

$s_{\mathrm{C}}(T)=s_{\mathrm{c}}^{0}(1+1.33(T-25))$ for $T \in[25 ; 100]$,

$s_{\mathrm{m}}(T)=s_{\mathrm{m}}^{0}(1+0.033(T-25))$ for $T \in[25 ; 100]$,

where $s_{\mathrm{c}}^{0}=5 \cdot 10^{-6} \mathrm{~S} / \mathrm{cm}$ and $s_{\mathrm{m}}^{0}=2 \cdot 10^{-4} \mathrm{~S} / \mathrm{cm}$ are the assumed ion conductivity at room temperature of the coating and matrix, respectively. It should be noted that the approximations in Eqs. (5)-(8) are only valid in the temperature range $25-100{ }^{\circ} \mathrm{C}$. The diffusion coefficient of the fibre $D_{\mathrm{f}}$ in Table 2 is assumed constant, equal to the longitudinal diffusion coefficient for sized IMS65 fibres at $\mathrm{SOC}=0.5$ reported by Kjell et al. [36]. To evaluate the effects of an assumed constant diffusion coefficient of the fibre, the two cases of 
slow and fast diffusion are studied. The diffusion coefficients for these cases are assumed to be $D_{\mathrm{f}}=1.4 \cdot 10^{-14} \mathrm{~m}^{2} / \mathrm{s}$ and $D_{\mathrm{f}}=3.6 \cdot 10^{-12} \mathrm{~m}^{2} / \mathrm{s}$, respectively. This corresponds to the diffusion coefficients measured at $\mathrm{SOC}=0.05$ and $\mathrm{SOC}=1$ for sized IMS65 fibres, respectively [36].

\section{Semi-analytical framework}

The developed semi-analytical framework is an extension of the concentric cylinder model developed by Marklund et al. [20]. The three phases (fibre, coating and particle reinforced matrix) are split in $N$ cylinder sections as illustrated in Fig. 3. In the schematic illustration in Fig. 3 the fibre, coating and particle reinforced matrix phases are divided into $N_{\mathrm{f}}, N_{\mathrm{c}}$ and $N_{\mathrm{m}}$ cylinder sections, respectively. An increased number of cylinders in the fibre region is needed to resolve the lithium concentration distribution in the fibre. The number of cylinders in each phase can be altered to improve the resolution of the stress distribution as the stresses are only derived at the interfaces. The radial displacement at the $k$-th cylinder boundary is defined as

$u_{r}^{k}=A_{1}^{k} r+A_{2}^{k} r^{-1}$,

where $A_{1}^{k}$ and $A_{2}^{k}$ are unknown constants determined by solving for displacement and stress continuity. The longitudinal, radial and hoop stress at the $k$-th cylinder boundary reads

$$
\begin{aligned}
& \sigma_{1}^{k}=Q_{11}^{k} \varepsilon_{10}+2 A_{1}^{k} Q_{12}^{k}-\eta_{1}^{k}, \\
& \sigma_{r}^{k}=A_{1}^{k}\left(Q_{22}^{k}+Q_{23}^{k}\right)+A_{2}^{k}\left(Q_{23}^{k}-Q_{22}^{k}\right) r^{-2}+Q_{12}^{k} \varepsilon_{10}-\eta_{r}^{k}, \\
& \sigma_{\theta}^{k}=A_{1}^{k}\left(Q_{23}^{k}+Q_{33}^{k}\right)+A_{2}^{k}\left(Q_{33}^{k}-Q_{23}^{k}\right) r^{-2}+Q_{13}^{k} \varepsilon_{10}-\eta_{\theta}^{k},
\end{aligned}
$$


where $Q_{i j}^{k}(\bar{C}, T)$ is the $i j$ component of the stiffness matrix which depends on the lithium concentration and temperature (c.f. Eqs. (3)-(6)). The longitudinal strain is defined as $\varepsilon_{10}$ (1-dir in Fig. 3) and the expansion terms are defined as

$$
\begin{aligned}
& \eta_{1}^{k}=Q_{11}^{k}\left(\beta_{1}^{k} \Delta \bar{C}^{k}+\alpha_{1}^{k} \Delta T^{k}\right)+Q_{12}^{k}\left(\beta_{r}^{k} \Delta \bar{C}^{k}+\alpha_{r}^{k} \Delta T^{k}\right)+Q_{13}^{k}\left(\beta_{\theta}^{k} \Delta \bar{C}^{k}+\alpha_{\theta}^{k} \Delta T^{k}\right), \\
& \eta_{r}^{k}=Q_{12}^{k}\left(\beta_{1}^{k} \Delta \bar{C}^{k}+\alpha_{1}^{k} \Delta T^{k}\right)+Q_{22}^{k}\left(\beta_{r}^{k} \Delta \bar{C}^{k}+\alpha_{r}^{k} \Delta T^{k}\right)+Q_{23}^{k}\left(\beta_{\theta}^{k} \Delta \bar{C}^{k}+\alpha_{\theta}^{k} \Delta T^{k}\right), \\
& \eta_{\theta}^{k}=Q_{13}^{k}\left(\beta_{1}^{k} \Delta \bar{C}^{k}+\alpha_{1}^{k} \Delta T^{k}\right)+Q_{32}^{k}\left(\beta_{r}^{k} \Delta \bar{C}^{k}+\alpha_{r}^{k} \Delta T^{k}\right)+Q_{33}^{k}\left(\beta_{\theta}^{k} \Delta \bar{C}^{k}+\alpha_{\theta}^{k} \Delta T^{k}\right),
\end{aligned}
$$

where $\Delta \bar{C}^{k}$ and $\Delta T^{k}$ are the normalized change in lithium concentration and change in temperature, respectively, and are derived as described in sections 3.1 and 3.2. Due to the assumption of invariable diffusion coefficient of the fibre, the change in lithium concentration is simply obtained as the change in concentration with respect to the original state. The change in temperature on the other hand is derived as the sum of the heat generated in the preceding time steps. This is done in order to account for the change in internal resistance (related to the temperature dependency of the conductivities for the different phases) with change in temperature. The assumed expansion coefficients for the different phases are given in Table 2. The effective expansion coefficients for the particle reinforced matrix are estimated as [37]

$$
\begin{aligned}
& \alpha_{\mathrm{m}, \mathrm{eff}}=\alpha_{\mathrm{p}} V_{\mathrm{p}}^{*}+\alpha_{\mathrm{m}}\left(1-V_{\mathrm{p}}^{*}\right)+\frac{\left(\alpha_{\mathrm{p}}-\alpha_{\mathrm{m}}\right)}{\left(\frac{1}{K_{\mathrm{p}}}-\frac{1}{K_{\mathrm{m}}}\right)}\left(\frac{1}{K_{\mathrm{m}, \mathrm{eff}}}-\left(\frac{V_{\mathrm{p}}^{*}}{K_{\mathrm{p}}}+\frac{\left(1-V_{\mathrm{p}}^{*}\right)}{K_{\mathrm{m}}}\right)\right), \\
& \beta_{\mathrm{m}, \mathrm{eff}}=\beta_{\mathrm{p}} V_{\mathrm{p}}^{*}+\frac{\beta_{\mathrm{p}}}{\left(\frac{1}{K_{\mathrm{p}}}-\frac{1}{K_{\mathrm{m}}}\right)}\left(\frac{1}{K_{\mathrm{m}, \mathrm{eff}}}-\left(\frac{V_{\mathrm{p}}^{*}}{K_{\mathrm{p}}}+\frac{\left(1-V_{\mathrm{p}}^{*}\right)}{K_{\mathrm{m}}}\right)\right),
\end{aligned}
$$

where $V_{\mathrm{p}}^{*}$ is the volume fraction of particles in the matrix and $K_{\mathrm{p}}$ and $K_{\mathrm{m}}$ are the bulk moduli of the particles and matrix, respectively. The effective bulk modulus of the particle reinforced matrix $K_{\mathrm{m}, \text { eff }}$ is derived as explained in [21] based on work by Hashin [38]. The 
displacement and stresses are derived by solving for continuity as described in the following. At the symmetry axis the displacement is set to zero

$u_{r}^{1}(r=0)=0$

Displacement and stress continuity conditions on all cylinder interfaces are defined as

$u_{r}^{k}\left(r_{k}\right)=u_{r}^{k+1}\left(r_{k}\right)$ and $\sigma_{r}^{k}\left(r_{k}\right)=\sigma_{r}^{k+1}\left(r_{k}\right)$.

Furthermore, the radial stress on the outer boundary is set to zero

$\sigma_{r}^{N}\left(r_{N}\right)=0$

Generalized plain strain is assumed. Hence, the strain in the longitudinal direction must result in zero average stress $\left(\sigma_{1}^{\mathrm{avg}}\right)$ in the same direction

$\sigma_{1}^{\mathrm{avg}}=\frac{2}{r_{N}^{2}} \sum_{k=1}^{N} \int_{r_{k-1}}^{r_{k}} r \sigma_{1} d r=\frac{2}{r_{N}^{2}} \sum_{k=1}^{N}\left(\left(Q_{11}^{k} \varepsilon_{10}+2 A_{1}^{k} Q_{12}^{k}-\eta_{1}^{k}\right) \frac{\left(r_{k}^{2}-r_{k-1}^{2}\right)}{2}\right)=0$

The unknown constants $A_{1}^{k}$ and $A_{2}^{k}$ and the longitudinal stain $\varepsilon_{10}$ are determined by solving the system of equations Eqs. (18)-(20) for different values of $\varepsilon_{10}$ while checking if Eq. (21) is fulfilled (compare with original model by Marklund et al. [20]). The internal stresses at time $t$ are derived as the total stresses (c.f. Eqs. (10)-(12)) with respect to the change in lithium concentration $\Delta \bar{C}^{k}$ and temperature $\Delta T^{k}$ at the given time.

\subsection{Change in lithium concentration}

The change in lithium concentration in the active electrode materials (fibres and particles) are governed by Fick's second law of diffusion. In this analysis the concentration gradient in the electrode particles is assumed to be zero. Hence, the lithium concentration within the particles is assumed constant at each time step. Fick's law in cylindrical coordinates describing the concentration distribution in the fibres (under the assumption that the diffusion coefficient is invariable) reads 
$\frac{\partial C_{\mathrm{f}}}{\partial t}=D_{\mathrm{f}} \frac{1}{r} \frac{\partial}{\partial r}\left(r \frac{\partial C_{\mathrm{f}}}{\partial r}\right)$

The initial lithium concentration at discharged state is assumed to be zero in the fibres and fully saturated in the particles. Furthermore, galvanostatic conditions are assumed which means that the flux of lithium at the surface of the electrodes is constant and equal to current density $i\left(\mathrm{~A} / \mathrm{m}^{2}\right)$ divided by Faraday's constant $F$. The lithium flux at the symmetry axis $(r=0)$ is set to zero. These conditions provide the boundary conditions to the diffusion problem and reads

$C_{\mathrm{f}}=0$ and $C_{\mathrm{p}}=C_{\mathrm{sat}}^{\mathrm{p}}, \quad$ for $t=0$,

$D_{\mathrm{f}} \frac{\partial C}{\partial r}=\frac{i_{\text {cell }}}{F}=\frac{I_{\text {cell }}}{2 \pi r_{\mathrm{f}} L_{\mathrm{lam}} F}, \quad$ for $r=r_{\mathrm{f}}$ and $t \in\left[0 ; t_{c}\right]$,

$D_{\mathrm{f}} \frac{\partial C}{\partial r}=0, \quad$ for $r=0$,

where $t_{c}$ is the time for charge/discharge. The current in each cell/fibre is defined as the applied current to the lamina divided by the number of fibres $I_{\text {cell }}=I_{\text {lam }} / n_{\mathrm{f}}$. This current is applied for a time $t_{c}=1 / C_{\text {rate }}$ (hours) and is determined based on the total capacity of the lamina and the applied C-rate as

$I_{\text {lam }}=\min \left(\Gamma_{\mathrm{f}} m_{\mathrm{f}} ; \Gamma_{\mathrm{p}} m_{\mathrm{p}}\right) C_{\text {rate }}$

In Eq. (26) $m_{\mathrm{f}}$ and $m_{\mathrm{p}}$ are the total mass of the fibres and particles in the lamina, respectively. An analytical solution to the boundary value problem above is expressed as [39]

$\bar{C}_{\mathrm{f}}(r, t)=\frac{i_{\text {cell }} r_{\mathrm{f}}}{C_{\mathrm{sat}}^{\mathrm{f}} D_{\mathrm{f}} F}\left(\frac{2 D_{\mathrm{f}} t}{r_{\mathrm{f}}^{2}}+\frac{r^{2}}{2 r_{\mathrm{f}}^{2}}-\frac{1}{4}-2 \sum_{n=1}^{\infty} \frac{J_{0}\left(\lambda_{n} r / r_{\mathrm{f}}\right)}{\lambda_{n}^{2} J_{0}\left(\lambda_{n}\right)} \exp \left(\frac{-D_{\mathrm{f}} t \lambda_{n}^{2}}{r_{\mathrm{f}}^{2}}\right)\right)$,

where $J_{0}(r)$ is the zero-order Bessel's function of the first kind and $\lambda_{n}$ is the $n$-th root of $J_{1}(\lambda)$. The radius of the fibre is defined as $r_{\mathrm{f}}$ and $t$ is the time. The lithium concentration distribution in the fibre is solved at each cylinder surface for each time step. Furthermore, the 
lithium concentration is normalized with respect to the saturated concentration $\left(C_{\mathrm{sat}}^{\mathrm{f}}=0.026\right.$ $\mathrm{mol} / \mathrm{m}^{3}$ ) based on the electrochemical capacities of the fibres at a C-rate of $0.08\left(\Gamma_{\mathrm{f}}^{0}\right)$. The change in lithium concentration in the fibre at the $k$-th cylinder surface at time $t$ is finally defined as

$\Delta \bar{C}_{\mathrm{f}}^{k}=\int_{0}^{t} \bar{C}_{\mathrm{f}}^{k}\left(r^{k}, t\right) d t=\bar{C}_{\mathrm{f}}^{k}\left(r^{k}, t\right)-\bar{C}_{\mathrm{f}}^{k}\left(r^{k}, 0\right)$

\subsection{Change in temperature}

The change in temperature due to heat generation during electrochemical cycling is derived as follows. The thermal energy balance can be expressed as

$$
m c_{p} \frac{\partial T}{\partial t}=Q_{\mathrm{gen}}+q_{\mathrm{ext}}
$$

where $m$ is the mass, $c_{p}$ is the specific heat, $Q_{\text {gen }}$ is the generated heat and $q_{\text {ext }}$ is the heat exchange with the surroundings. In the structural battery lamina each concentric cylinder (illustrated in Fig. 3) corresponds to one battery cell. These cells are connected in parallel which means the process for critical cells/fibres located in the middle of the lamina can be considered adiabatic (i.e. no transfer of heat between the thermodynamic system and its surroundings $q_{\text {ext }}=0$ ). This can be motivated by the fact that each cell will generate the same heat and given the low thermal conductivity of the surrounding polymer matrix only minor heat dissipation will occur for critical cells. Moreover, the individual laminae will be stacked in a laminate and need to be protected against moisture and oxygen. This means that heat transfer between the battery cells and the surrounding will be further limited in the final application. The heat generation term $Q_{\text {gen }}$ in Eq. (29) is defined as

$Q_{\mathrm{gen}}=Q_{\mathrm{ohm}}+Q_{\mathrm{rev}}+Q_{\mathrm{rxn}}$

where $Q_{\mathrm{ohm}}$ is the ohmic heat generation rate, $Q_{\mathrm{rev}}$ is the reversible heat generation rate and $Q_{\text {rxn }}$ is the reaction heat generation rate. In this study, the heat generation terms $Q_{\text {rev }}$ and 
$Q_{\text {rxn }}$ are neglected since they are assumed to be small in comparison with $Q_{\mathrm{ohm}}$ due to the relatively high electrical resistance of the constituents compared to counterparts in ordinary lithium ion batteries. Under the assumption that Ohm's law is applicable, the ohmic heat generation rate in Eq. (30) can be defined with respect to the current $I$ and resistance $R$ as

$Q_{\mathrm{ohm}}=R I^{2}$

The ohmic heat generation rate is related to the heat generated due to motion of charged species in the different phases. In the polymer coating and matrix heat is mainly generated due to motion of lithium ions while in the fibre and carbon black particles in the matrix heat is generated due to motion of electrons. The resistance of the paths in the carbon fibre $\left(R_{\mathrm{f}}\right)$, the polymer coating $\left(R_{\mathrm{c}}\right)$, the polymer matrix $\left(R_{\mathrm{m}}\right)$ and the carbon black particles $\left(R_{\mathrm{cb}}\right)$ are defined as

$R_{\mathrm{f}}=\frac{L_{\mathrm{lam}}}{2 r_{\mathrm{f}}^{2} \pi s_{\mathrm{f}}}, \quad R_{\mathrm{c}}=\frac{\ln \left(r_{\mathrm{c}} / r_{\mathrm{f}}\right)}{2 \pi L_{\mathrm{lam}} s_{\mathrm{c}}}, \quad R_{\mathrm{m}}=\frac{\ln \left(\left(r_{\mathrm{c}}+0.5\left(r_{\mathrm{m}}-r_{\mathrm{c}}\right)\right) / r_{\mathrm{c}}\right)}{2 \pi L_{\mathrm{lam}} s_{\mathrm{m}}}, \quad R_{\mathrm{cb}}=\frac{\delta_{\mathrm{lam}}}{2 r_{m} L_{\mathrm{lam}} s_{\mathrm{cb}}}$.

In Eq. (32) $s_{\mathrm{f}}$ and $s_{\mathrm{cb}}$ are the electrical conductivity of the fibre and carbon black particles respectively, while $s_{\mathrm{c}}$ and $s_{\mathrm{m}}$ are the ion conductivity of the coating and matrix, respectively, given in Table 2. The area for electron transport in the matrix via carbon black particles is assumed to be $r_{m} L_{\mathrm{lam}}$ and the electric conductivity of the particle reinforced matrix is assumed to be equal to the conductivity of the carbon black particles.

Inserting Eqs. (30) and (31) in (29) the change in temperature with time can be expressed as $\frac{\partial T}{\partial t}=\frac{R I^{2}}{m c_{p}}$

The generated heat in one cell at time $t$ is derived as the sum of the heat generated in the preceding time steps $\left(n_{\text {step }}\right)$ defined as 
$\Delta T_{\text {cell }}=\sum_{i=1}^{n_{\text {step }}}\left(\int_{t_{i-1}}^{t_{i}} \frac{R_{\text {cell }, i} I_{\text {cell }}^{2}}{m_{\text {cell }} c_{p}^{\text {avg }}} d t\right)=\sum_{i=1}^{n_{\text {step }}}\left(\frac{R_{\text {cell }, i} I_{\text {cell }}^{2}}{m_{\text {cell }} c_{p}^{\text {avg }}}\left(t_{i}-t_{i-1}\right)\right)$

where $m_{\text {cell }}$ is the mass of the cell. The total resistance for the cell $\left(R_{\text {cell }, i}\right)$ at the $i$-th time step corresponds to the sum of the resistances for the individual phases Eq. (32). Due to the temperature dependency of the conductivity for the different phases the total resistance will vary with temperature. Changes in resistances due to volume changes during electrochemical cycling are neglected as these variations are assumed to be small compared with changes related to conductivities. The weighted average of the specific heat in Eq. (34) reads

$c_{p}^{\mathrm{avg}}=\frac{1}{m_{\mathrm{tot}}} \sum_{j=1}^{5} m_{j} c_{p, j}$

where $j$ corresponds to the $j$-th phase (fibre, coating, matrix and $\mathrm{LiFePO}_{4}$ and carbon black particles). The total mass is defined as $m_{\text {tot }}$ and the mass and specific heat of the $j$-th phase are defined as $m_{j}$ and $c_{p, j}$, respectively.

\section{Computational model}

The FE-model used to validate the semi-analytical framework is a 2D axisymmetric model set up in COMSOL 5.3a. The displacements along the symmetry-axis $(r=0)$ are set to zero and the external surface $\left(r=r_{\mathrm{m}}\right)$ is free to expand. Generalized plain strain is assumed as for the semi-analytical framework. Hence, the dimension in z-direction (corresponds to 1-dir in Fig. 3) can be set to any value (in this model $5 \mu \mathrm{m}$ was used) as the stresses along the $\mathrm{z}$ direction are constant. The model uses 2D axisymmetric elements and orthotropic material properties that depend on lithium concentration and temperature in accordance with assumptions outlined in section 2. The lithium concentration in the fibre, is approximated using the 1D axisymmetric diffusion model presented in section 3 , which provides input on the resulting expansion and stiffness of the active materials for each time step. The change in 
temperature inside the domain is derived using Eq. (34) and is given as input value to the FEmodel.

\section{Results and discussion}

\subsection{Influence of $C$-rate on internal stresses}

The internal stresses in the fully charged 3D structural battery are calculated for different Crates. Model predictions for C-rates 0.08 and 6 are presented in Fig. 4. For $C_{\text {rate }}=6$ the internal stresses are significantly lower compared to those generated at $C_{\text {rate }}=0.08$. This is primarily a consequence of the lower diffusion induced volume change of the active electrode materials with the reduced electrochemical capacity (for increased C-rate). For example, the largest hoop stress in the matrix is found for $C_{\text {rate }}=0.08$. This stress is in tension which means that it may cause crack initiation in the matrix. It should be noted that due to the low electrochemical capacity of the fibres compared to the particles at high C-rates the lithium concentration in the fibres is only about $15 \%$ at $\mathrm{SOC}=1$ for a C-rate of 6.

The heat generated during charging at $C_{\text {rate }}=1\left(\Delta T=9.6^{\circ} \mathrm{C}\right)$ is about five to two times higher than at a $\mathrm{C}$-rate of 0.08 or $6\left(\Delta T=2.2^{\circ} \mathrm{C}\right.$ and $\Delta T=5.5^{\circ} \mathrm{C}$, respectively $)$. This may seem contradictory to the assumption that increased current will lead to increased heat generation (c.f. Eq. (34)). However, the total current needed to fully charge the battery depends on the electrochemical capacity of the cell. This capacity is reduced with increased C-rate (c.f. Eqs. (1) and (2)). It should be noted that the results from the semi-analytical framework (SAF) and FE-model (FEM) are both presented in Fig. 4. The predictions from the semi-analytical framework and the FE-model show excellent agreement. In the continuation, only the results from the semi-analytical framework are presented (FE-model still used for validation). 
In Fig. 5 the longitudinal stress is plotted for different diffusion rates (i.e. different diffusion coefficients of the fibre) after being charged at a C-rate of 0.08 and 1. For both cases the internal stresses in the polymer phases are accurately predicted assuming a constant diffusion coefficient of the fibre. Moreover, for low $\mathrm{C}$-rate $\left(C_{\text {rate }} \sim 0.08\right)$ the difference in stress state in the fibre between slow and fast diffusion is small (Fig. 5a). This shows that for low C-rate the stress state in the fibre developed during galvanostatic cycling can be approximated assuming a constant diffusion coefficient. In the case of slow diffusion and high C-rate (Fig. 5b), there is a strong variation of the longitudinal stresses over the fibre radius. With increased diffusion rate this variation is not present due to the increased diffusivity of the fibre. These findings are in agreement with previous findings by Xu et al. [15]. Hence, the internal stress state in the fibre is highly affected by the diffusion rate at high C-rates, while at low C-rates the stresses in the fibre are not. Neither are the stresses in the coating and matrix phases affected by the diffusion rate at low C-rates. In the current assessment of the thermal effects on the internal stress state, the error due to the assumption of invariable diffusion coefficient of the fibre is considered negligible. Based on these results it is evident that one has to access stress states for different C-rates and different diffusion rates when evaluating the mechanical performance of the structural battery.

The longitudinal stress is plotted in Fig. 6 for the two cases: $n_{\text {step }}=1$ and $n_{\text {step }}=4$, when charging at $C_{\text {rate }}=1$. For the case of one time step the heat generated during charge is $\Delta T=10^{\circ} \mathrm{C}$ while for $n_{\text {step }} \geq 4 \Delta T \sim 9.6^{\circ} \mathrm{C}$. This illustrates that the number of time steps used for deriving the change in temperature (c.f. Eq. (34)) only have minor effect on the resulting stress distribution for the studied cases. In the continuation $n_{\text {step }}=4$ is used.

It should also be noted that the validity of the assumption that no heat exchange occurs between the unit cell and its surrounding (adiabatic process) is stronger for higher C-rates. This is due to the fact that the $\mathrm{C}$-rate refers to the time for charge/discharge. For low C-rates, 
e.g. 0.08 , the time for discharge is 12.5 hours. As the heat is generated during such a long time span one can assume that even with low thermal conductivity of the surrounding polymer matrix some of the generated heat will dissipate during the charge/discharge cycle. Nevertheless, for high C-rates the assumption of adiabatic conditions is assumed valid. Moreover, the validity of the assumption that the ohmic heat generation rate is the dominating heat source is also stronger for higher C-rates. The error due to these assumptions for low C-rates is considered negligible as only small temperature changes are recorded for these cases.

\subsection{Influence of lamina dimensions on internal stresses}

To evaluate how the lamina dimensions affect the internal stresses three composite laminae with different dimensions are studied (Fig. 7). The three cases represent three potential lamina sizes applicable for this material. The hoop stresses for the three cases after being charged at $C_{\text {rate }}=1$ are presented in Fig. 7 . The heat generated during charging inside the material for the medium and small lamina (case 1 and 3) are $9.8^{\circ} \mathrm{C}$ and $3.4{ }^{\circ} \mathrm{C}$, respectively. For the large lamina (case 2) the generated heat is $35^{\circ} \mathrm{C}$. For the smallest lamina (case 3), most of the heat is generated due to ohmic losses from electron transport via the carbon black particles in the matrix. When increasing the length of the lamina the internal resistance of the electron transport in the fibres becomes the dominating factor for heat generation. In case 2 (largest lamina) the hoop stresses decrease due to the reduced stiffness of the coating and matrix with increased temperature. Hence, the restriction of the expansion of the carbon fibre is reduced resulting in lower internal stresses. For the given cases the highest stresses are found for the smallest size lamina (case 3). Hence, the dimensions of the lamina will play an important role in the design of a structural battery composite component. 
It should be noted that increased temperature can also lead to electrical failure (e.g. thermal runaway). This means that the temperature evolution is important to account for when evaluating the electrical performance of the material.

\subsection{Influence of residual stresses on internal stresses}

In Fig. $8 \mathrm{a}$ and $\mathrm{b}$ the thermal induced residual stresses from manufacturing and the diffusion induced residual stresses from irreversible volume change of the active electrode materials are presented. The composite is assumed to be cured at $90^{\circ} \mathrm{C}$ and subsequently cooled down to room temperature $\left(25^{\circ} \mathrm{C}\right)$. Chemical shrinkage due to curing of the matrix is neglected. The residual stresses from irreversible volume changes are caused by trapped lithium in the electrode materials and solid electrolyte interphase (SEI) formation. This occurs during the first charge/discharge cycles. These cycles are assumed to be performed subsequent to curing at very low C-rates in controlled environment (as done for ordinary lithium ion batteries). For this reason, the diffusion and SEI formation-induced stresses due to these volume changes are considered as additional residual stresses within the material. In this analysis, these volume changes are assumed to be $0.59 \beta$, approximated based on experimental data [27]. It should be noted that the irreversible expansion/shrinkage of the electrode materials is considered as a one-time event. This assumption is made to simplify the analysis and is motivated by the fact that only small volume changes have been reported due to the continuous change of the SEI layer with repeated electrochemical cycling after the first charge/discharge cycles. For refined damage models, the accumulation of SEI formation-induced stresses should be accounted for in future studies [40]. In Fig. 8c and d the combined/superimposed load case of residual stresses from manufacture and irreversible volume changes and stresses developed during electrochemical cycling after being charged and discharged at $C_{\text {rate }}=1$ are presented. The residual stresses from manufacture (Fig. 8a) and irreversible volume changes (Fig. 8b) are found to have a significant effect on the internal stress state. These residual stresses are 
enhanced during charging. When discharged the stresses are relieved as the diffusion induced volume changes create stresses of opposite signs (compared with previous states) while additional heat is generated. The results clearly indicate that it is important to consider the residual stresses to accurately resolve the internal stresses.

\subsection{Elastic properties}

In earlier work by the authors [21] the state of charge was shown to have a significant effect on the elastic properties of this type of material. In that study, only extremes in SOC were considered and thermal effects were neglected. Here the effects on electrochemical cycling on the internal stresses in a structural battery composite are addressed. The results show that in large lamina, charged at high currents, the generated heat will be significant. The increased temperature will influence the elastic properties of the constituents. For example, assuming that the larger lamina (case 2 in section 5.2) has the properties of the baseline configuration of the composite lamina studied in [21] is charged at a C-rate of $1\left(\Delta T \approx 35^{\circ} \mathrm{C}\right)$. For this case the change in the transverse stiffness of the lamina between fully charged and discharged state is estimated to be approximately $-50 \%$, instead of $+4 \%$ as predicted in [21], if the generated heat is retained within the material as charged. This stiffness change is related to the reduced moduli of the coating and matrix with increased temperature. This further illustrates the importance of accounting for the thermal effects when evaluating the mechanical performance of structural battery composites.

\section{Conclusions}

Electrochemical cycling of the structural battery will generate heat and cause the active electrode materials to expand or shrink. This will induce internal stresses within the material which may cause mechanical and/or electrical failure. In previous studies on structural batteries only the diffusion induced stresses due to change in lithium concentration in the electrode materials have been studied, without considering the generated heat from 
electrochemical cycling. To investigate the importance of thermal effects on the internal stress state a semi-analytical framework has been developed. By simplifying the general multiphysics problem (involving multiple coupled physical phenomena), the developed model provides a practical tool for analysis of the internal stress state of the structural battery during electrochemical cycling. Moreover, the model provides a powerful tool for parametric studies and validation of future extended multiphysics models.

In this study the proposed model is used to estimate the internal stresses in a $3 \mathrm{D}$ structural battery composite due to a combination of heat generation and volume change of electrode materials occurring during electrochemical cycling. Furthermore, the model is used to evaluate how the internal stress state is affected by charging/discharging current, lamina dimensions and residual stresses. The results show that the heat generation during electrochemical cycling must be accounted for when evaluating the internal stress state in this material. For a C-rate of 1 and large lamina dimensions a temperature increase of approximately $35^{\circ} \mathrm{C}$ is reported at full charge. This temperature increase has a significant effect on the internal stresses as it results in thermal induced stresses and alters the properties of the constituents. Due to the reduced electrochemical capacity of the active electrode material with increased C-rate and reduced modulus of the coating with increased temperature, it is found that the highest stresses occur for low C-rates in small laminae. Furthermore, it is found that the residual stresses have significant effect on the internal stress state. It is also found that the stress state in the polymer phases can be accurately predicted assuming a constant diffusion coefficient of the fibre. Moreover, the stress state in the fibre can be approximated for low C-rate using the proposed framework, while for accurate predictions at higher C-rate the non-linear variation of the diffusion coefficient should be accounted for in future studies. Moreover, to evaluate the severity of the stresses developed during operation failure models are needed e.g. building on the work by Bucci et al. [41]. 


\section{Acknowledgements}

This project has been funded by the European Union, Clean Sky Joint Undertaking 2, Horizon 2020 under Grant Agreement Number 738085 and USAF, contract FA9550-17-10338, which are gratefully acknowledged.

\section{References}

[1] G. Fredi, et al., Graphitic microstructure and performance of carbon fibre Li-ion structural battery electrodes, Multifunct. Mater. 1 (2018) 015003.

[2] M.H. Kjell, E. Jacques, D. Zenkert, M. Behm, G. Lindbergh, PAN-based carbon fiber negative electrodes for structural lithium-ion batteries, J. Electrochem. Soc. 158 (2011) A1455-A1460.

[3] E.D. Wetzel, Reducing weight: Multifunctional composites integrate power, communications and structure, AMPTIAC Q. 8(4) (2004) 91-95.

[4] D.J. O’Brien, D.M. Baechle, E.D. Wetzel, Design and performance of multifunctional structural composite capacitors, J. Compos. Mater. 45, (2011) 2797-2809.

[5] E. Wong, D. Baechle, K. Xu, R.H. Carter, J.F. Synder, E.D. Wetzel, Design and Processing of Structural Composite Batteries, in: Proc. Soc. Adv. Mater. Process Eng., Baltimore, USA, 2007.

[6] S. Ekstedt, M. Wysocki, L.E. Asp, Structural batteries made from fibre reinforced composites, Plast. Rubber Compos. 39 (2010) 148-150.

[7] T. Carlson, Multifunctional composite materials - design, manufacture and experimental characterisation, Doctoral Thesis, Luleå University of Technology, Luleå, Sweden, 2013.

[8] L.E. Asp, A. Bismarck, T. Carlson, G. Lindbergh, S. Leijonmarck, M. Kjell, A battery half-cell, a battery and their manufacture (structural battery). PCT, Patent No. 2893582, November 16th 2016. (Intl Appl No. PCT/EP2013/068024, 2013). 
[9] L.E. Asp, E.S. Greenhalgh, Structural power composites, Compos. Sci. Technol. 101 (2014) 41-61.

[10] C. Hendricks, N. Williard, S. Mathew, M. Pecht, A failure modes, mechanisms, and effects analysis (FMMEA) of lithium-ion batteries, J. Power Sources. 297 (2015) 113120.

[11] N. Ihrner, W. Johannisson, F. Sieland, D. Zenkert, M. Johansson, Structural lithium ion battery electrolytes: Via reaction induced phase-separation, J. Mater. Chem. A. 5 (2017) 25652-25659.

[12] M. Willgert, M.H. Kjell, E. Jacques, M. Behm, G. Lindbergh, M. Johansson, Photoinduced free radical polymerization of thermoset lithium battery electrolytes, Eur. Polym. J. 47 (2011) 2372-2378.

[13] K. Xu, Nonaqueous liquid electrolytes for lithium-based rechargeable batteries, Chem. Rev. 104 (2004) 4303-4417.

[14] A. Pupurs, J. Varna, Modeling mechanical stress and exfoliation damage in carbon fiber electrodes subjected to cyclic intercalation/deintercalation of lithium ions, Compos. Part B Eng. 65 (2014) 69-79.

[15] J. Xu, G. Lindbergh, J. Varna, Carbon fiber composites with battery function: Stresses and dimensional changes due to Li-ion diffusion, J. Compos. Mater. 52 (2018) 2729_ 2742.

[16] J. Xu, G. Lindbergh, J. Varna, Multiphysics modeling of mechanical and electrochemical phenomena in structural composites for energy storage: Single carbon fiber micro-battery, J. Reinf. Plast. Compos. 37 (2018) 701-715.

[17] F. Dionisi, R. Harnden, D. Zenkert, A model to analyse deformations and stresses in structural batteries due to electrode expansions, Compos. Struct. 179 (2017) 580-589.

[18] W. Wu, X. Xiao, X. Huang, S. Yan, A multiphysics model for the in situ stress 
analysis of the separator in a lithium-ion battery cell, Comput. Mater. Sci. 83 (2014) $127-136$.

[19] X. Zhang, A.M. Sastry, W. Shyy, Intercalation-Induced Stress and Heat Generation within Single Lithium-Ion Battery Cathode Particles, J. Electrochem. Soc. 155 (2008) A542-A552.

[20] E. Marklund, J. Varna, Modeling the hygroexpansion of aligned wood fiber composites, Compos. Sci. Technol. 69 (2009) 1108-1114.

[21] D. Carlstedt, E. Marklund, L.E. Asp, Effects of state of charge on elastic properties of 3D structural battery composites, Compos. Sci. Technol. 169 (2019) 26-33.

[22] E. Jacques, M.H. Kjell, D. Zenkert, G. Lindbergh, M. Behm, Impact of mechanical loading on electrochemical performance of carbon fibres, in: Proc. 18th Int Conf Compos. Mater., Jeju, South Korea, 2011.

[23] S. Leijonmarck, T. Carlson, G. Lindbergh, L.E. Asp, H. Maples, A. Bismarck, Solid polymer electrolyte-coated carbon fibres for structural and novel micro batteries, Compos. Sci. Technol. 89 (2013) 149-157.

[24] D. Carlstedt, W. Johannisson, D. Zenkert, P. Linde, L.E. Asp, Conceptual Design Framework for Laminated Structural Battery Composites, in: Proc. 18th Eur. Conf. Compos. Mater., Athens, Greece, 2018.

[25] N.A. Mohd Radzuan, A.B. Sulong, J. Sahari, A review of electrical conductivity models for conductive polymer composite, Int. J. Hydrogen Energy. 42 (2017) 92629273.

[26] P. Hou, G. Chu, J. Gao, Y. Zhang, L. Zhang, Li-ion batteries: Phase transition, Chinese Phys. B 25 (2016) 016104.

[27] E. Jacques, M. Hellqvist Kjell, D. Zenkert, G. Lindbergh, M. Behm, Expansion of carbon fibres induced by lithium intercalation for structural electrode applications, 
Carbon N. Y. 59 (2013) 246-254.

[28] W.-J. Zhang, Comparison of the Rate Capacities of LiFePO4 Cathode Materials, J. Electrochem. Soc. 157 (2010) A1040.

[29] E. Jacques, M.H. Kjell, D. Zenkert, G. Lindbergh, The effect of lithium-intercalation on the mechanical properties of carbon fibres, Carbon N. Y. 68 (2014) 725-733.

[30] Y. Qi, H. Guo, L.G. Hector, A. Timmons, Threefold Increase in the Young's Modulus of Graphite Negative Electrode during Lithium Intercalation, J. Electrochem. Soc. 157 (2010) A558-A566.

[31] M. Willgert, M.H. Kjell, G. Lindbergh, M. Johansson, New structural lithium battery electrolytes using thiol-ene chemistry, Solid State Ionics. 236 (2013) 22-29.

[32] D.E. Bowles, S.S. Tompkins, Prediction of coefficients of thermal expansion for unidirectional composites, J. Compos. Mater. 23 (1989) 370-388.

[33] Y. Qi, L.G. Hector, C. James, K.J. Kim, Lithium Concentration Dependent Elastic Properties of Battery Electrode Materials from First Principles Calculations, J. Electrochem. Soc. 161 (2014) F3010-F3018.

[34] T. Maxisch, G. Ceder, Elastic properties of olivine Lix FePO4 from first principles, Phys. Rev. B - Condens. Matter Mater. Phys. 73 (2006) 1-4.

[35] M. Wysocki, L.E. Asp, S. Ekstedt, Structural Polymer Electrolyte for Use in Multifunctional Energy Storage Devices, in: Proc. 14th Eur. Conf. Compos. Mater., Budapest, Hungary, 2010.

[36] M.H. Kjell, T.G. Zavalis, M. Behm, G. Lindbergh, Electrochemical Characterization of Lithium Intercalation Processes of PAN-Based Carbon Fibers in a Microelectrode System, J. Electrochem. Soc. 160 (2013) A1473-A1481.

[37] R.M. Christensen, Mechanics of Composite Materials, Dover publications, Mineola, New York, 2005. 
[38] Z. Hashin, Analysis of Composite Materials, J. Appl. Mech. 50 (1983) 481-505.

[39] J. Crank, The Mathematics of Diffussion, Oxford University Press, London, 1975.

[40] E.M.C. Jones, Ö.Ö. Çapraz, S.R. White, N.R. Sottos, Reversible and irreversible deformation mechanisms of composite graphite electrodes in lithium-ion batteries, . Electrochem. Soc. 163 (2016) A1965-A1974.

[41] G. Bucci, T. Swamy, Y.M. Chiang, W.C. Carter, Modeling of internal mechanical failure of all-solid-state batteries during electrochemical cycling, and implications for battery design, J. Mater. Chem. A. 5 (2017) 19422-19430.

\section{Figures}

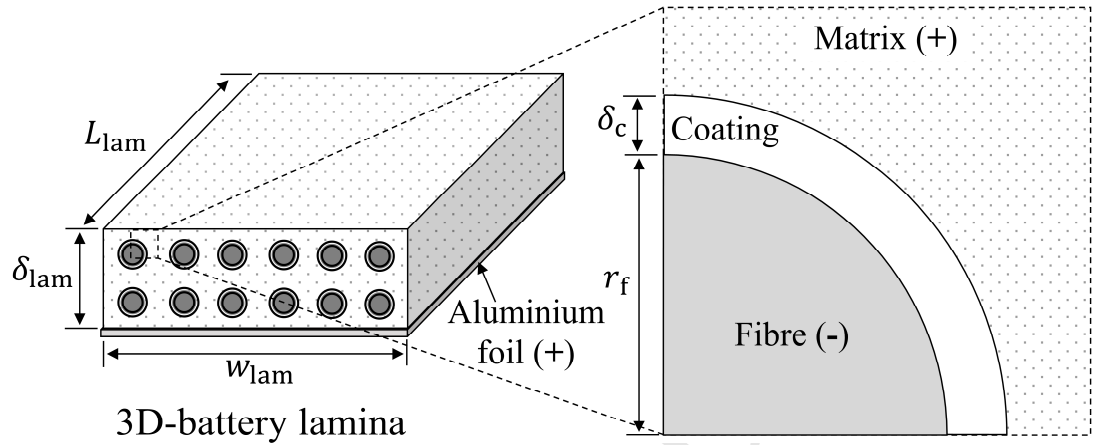

Battery cell constituents

Fibre: Negative electrode and current collector (neg.)

Matrix (particle reinforced):

Positive electrode

Coating: Electrolyte and separator

Aluminium foil: current collector (pos.)

Fig. 1. Schematic illustration of the 3D structural battery composite
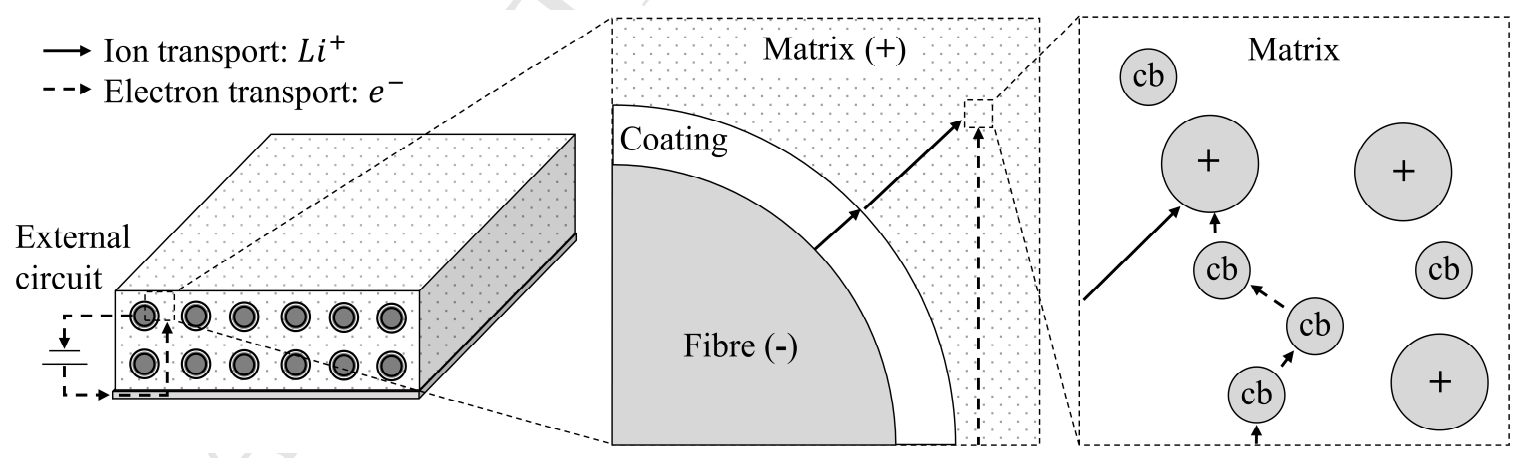

Fig. 2. Illustration of the path of the current inside the cell during discharge. For charging the direction of the arrows are reversed. 


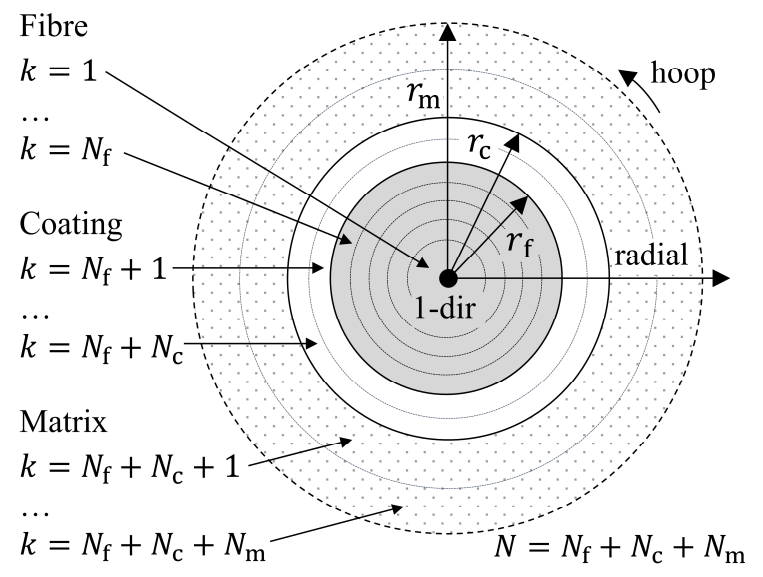

Fig. 3. In the semi-analytical framework, the three phases (fibre, coating and particle reinforced matrix) are split in additional cylinder sections to resolve the displacement and stress distribution.
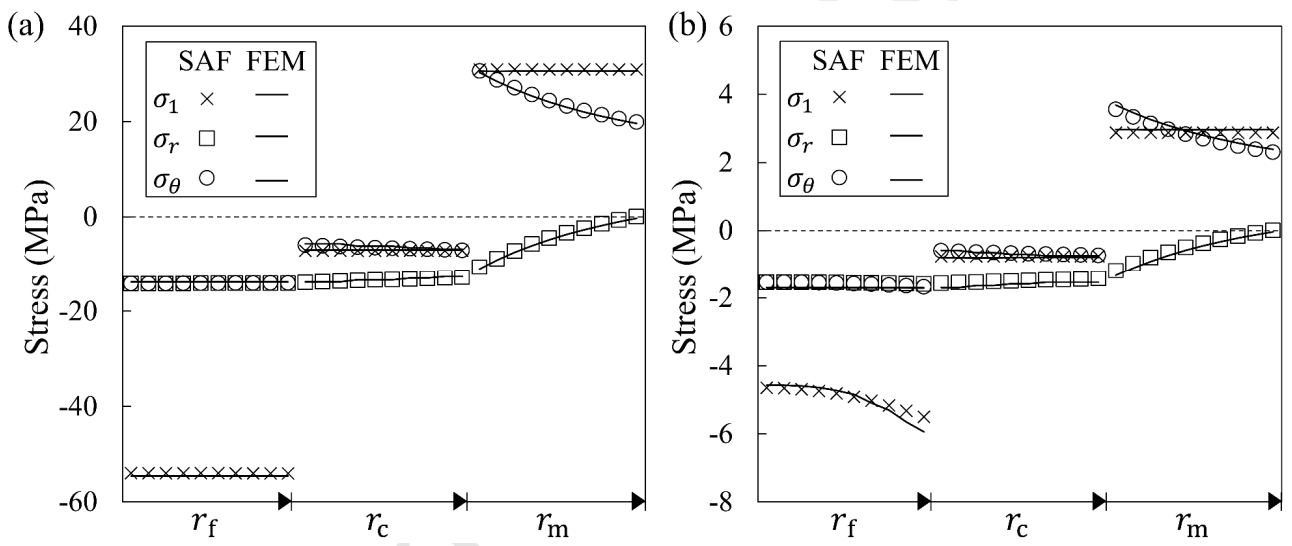

Fig. 4. Internal stresses after being fully charged at a C-rate of 0.08 (a) and a C-rate of 6 (b).

The acronym SAF stands for Semi-Analytical Framework and FEM for FE-model. 

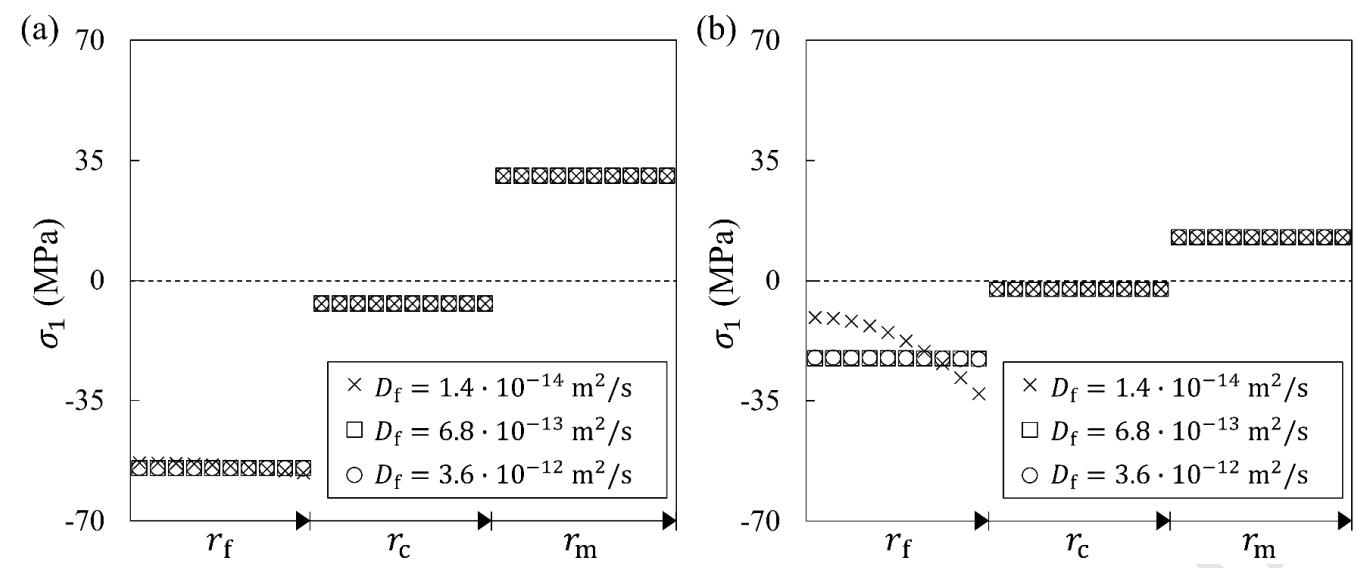

Fig. 5. Longitudinal stress distribution after being charged for different diffusion rates $\left(D_{f}=1.4 \cdot 10^{-14} \mathrm{~m}^{2} / \mathrm{s}\right.$ slow diffusion, $D_{f}=6.8 \cdot 10^{-13} \mathrm{~m}^{2} / \mathrm{s}$ medium diffusion and $D_{f}=$ $3.6 \cdot 10^{-12} \mathrm{~m}^{2} / \mathrm{s}$ fast diffusion). (a) Charged at $C_{\text {rate }}=0.08$. (b) Charged at $C_{\text {rate }}=1$.
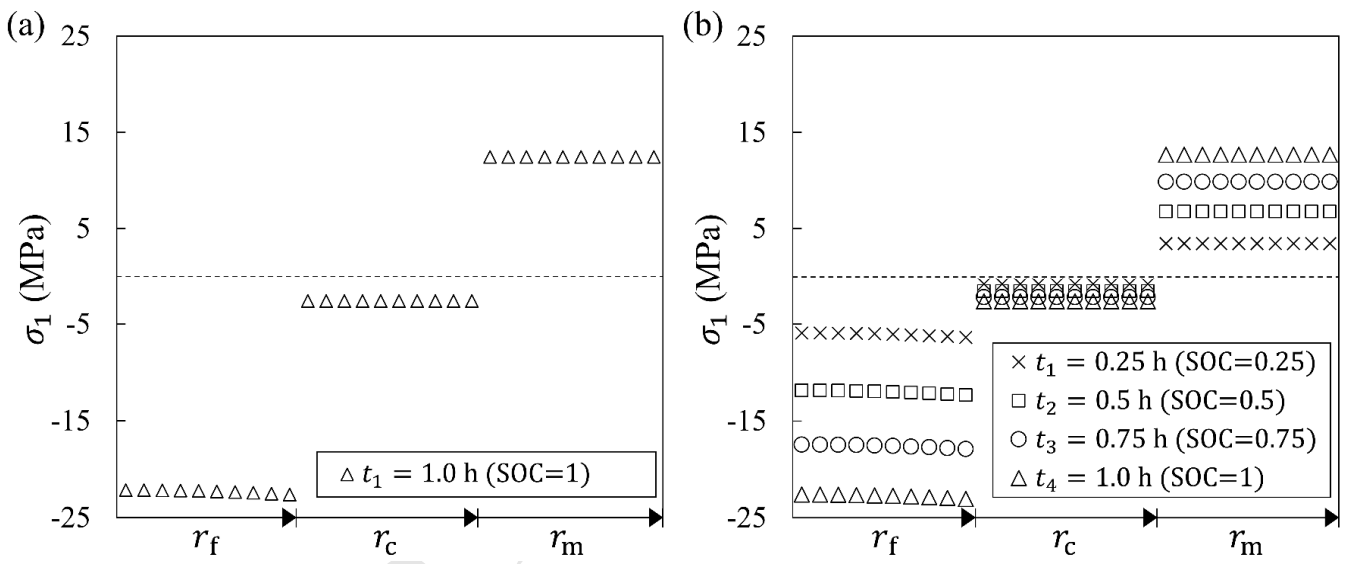

Fig. 6 The longitudinal stress distribution during charge at a C-rate of 1 when using different number of time steps to determine the generated heat during electrochemical cycling (c.f. Eq. (34)). (a) One time step $\left(n_{\text {step }}=1\right)$. (b) Four time steps $\left(n_{\text {step }}=4\right)$. 


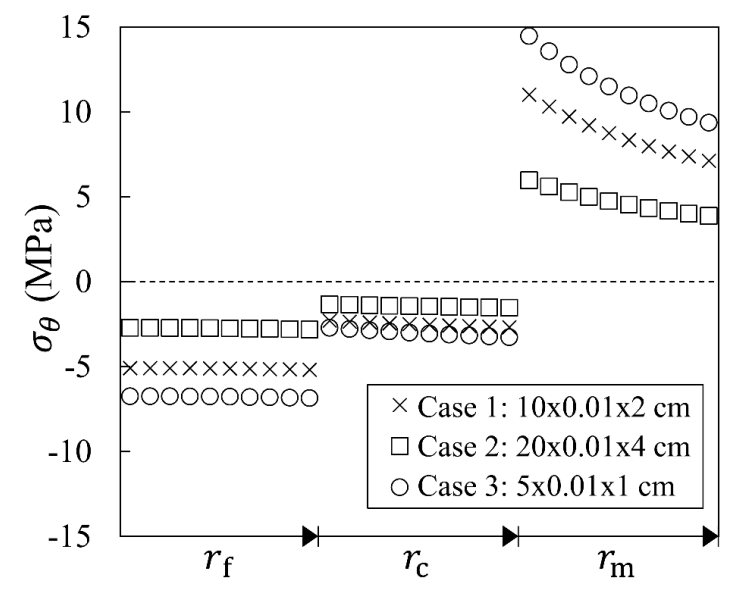

Fig. 7. Hoop stresses for different dimensions of the composite lamina after being charged at a C-rate of 1 . The dimensions are defined as $L_{\text {lam }} \times \delta_{\text {lam }} \times w_{\text {lam }}$. Case 1 (medium): 10x0.01x $2 \mathrm{~cm}$. Case 2 (large): 20x0.01x $4 \mathrm{~cm}$. Case 3 (small): $5 \times 0.01 \times 1 \mathrm{~cm}$.
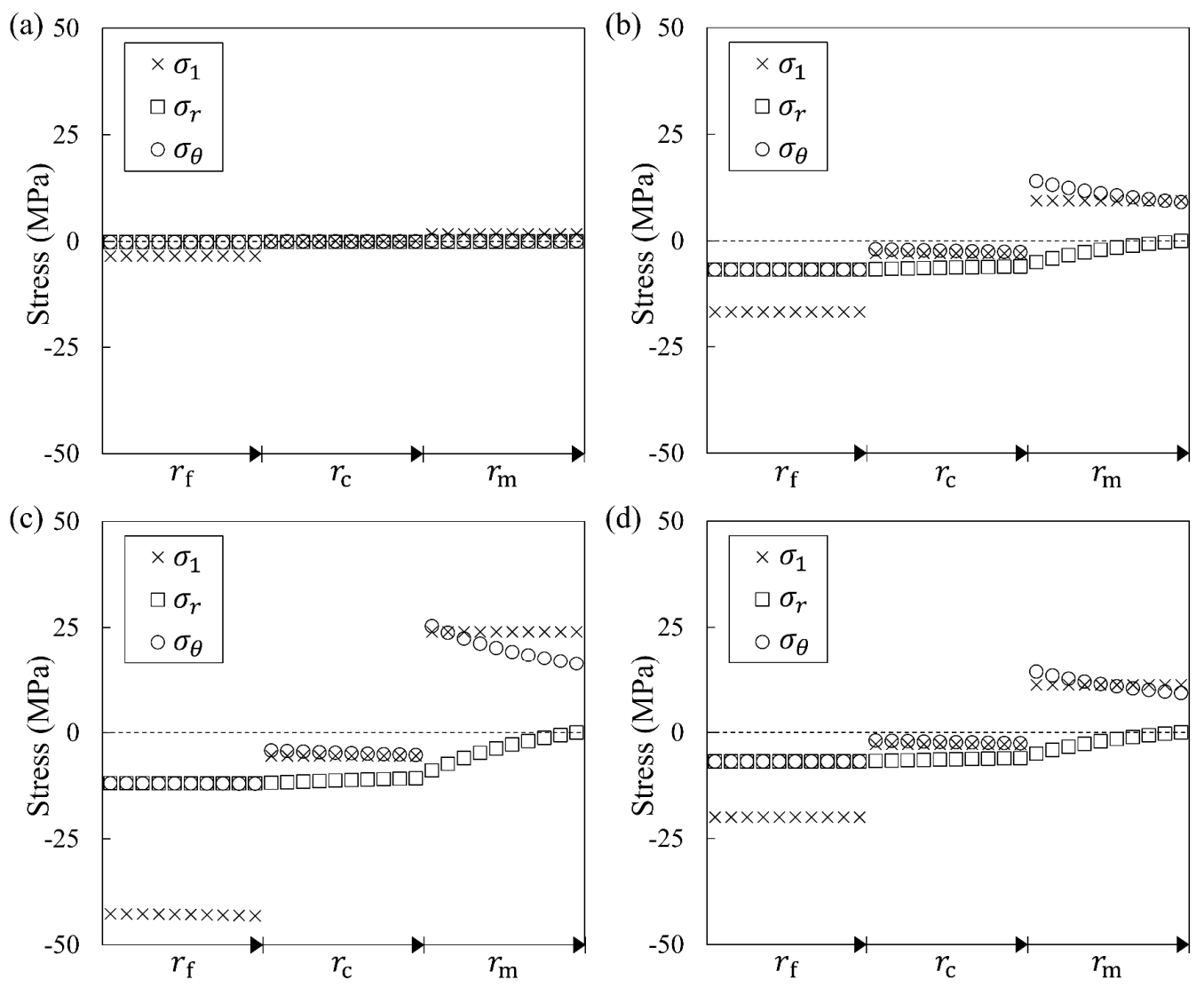

Fig. 8. (a) Residual stresses from manufacture. (b) Residual stresses from irreversible volume changes at $\mathrm{SOC}=0$. (c, d) Internal stresses, including residual stresses from $(\mathrm{a}, \mathrm{b})$, at $\mathrm{SOC}=1$ (c) and $\mathrm{SOC}=0$ (d) in operation at a C-rate of 1. 


\section{Tables}

Table 1. Assumed lengths of the individual paths for the current flow in the different phases.

\begin{tabular}{lll}
\hline Material phase & Length of current path & Specie \\
\hline Carbon fibre & $L_{\text {lam }} / 2$ & Electron \\
Polymer coating & $\delta_{\mathrm{c}}$ & Ion \\
Polymer matrix & $\left(r_{\mathrm{m}}-r_{c}\right) / 2$ & Ion \\
Carbon black particles in matrix & $\delta_{\mathrm{lam}} / 2$ & Electron \\
\hline
\end{tabular}

Table 2. Assumed properties of the constituents.

\begin{tabular}{lllllll}
\hline Property & $\begin{array}{l}\text { Carbon } \\
\text { fibre }(\mathrm{f})\end{array}$ & $\begin{array}{l}\text { Coating } \\
(\mathrm{c})\end{array}$ & $\begin{array}{l}\text { Matrix } \\
(\mathrm{m})\end{array}$ & $\begin{array}{l}\mathrm{LiFePO}_{4} \\
\text { particles } \\
(\mathrm{p})\end{array}$ & $\begin{array}{l}\text { CB } \\
\text { particles } \\
(\mathrm{cb})\end{array}$ & Reference \\
\hline$\Gamma(\mathrm{Ah} / \mathrm{g})$ & $\Gamma_{\mathrm{f}}\left(C_{\mathrm{rate}}\right)$ & - & - & $\Gamma_{\mathrm{p}}\left(C_{\mathrm{rate}}\right)$ & - & {$[27,28]$} \\
$E_{\mathrm{L}}(\mathrm{MPa})$ & $E_{\mathrm{L}, \mathrm{f}}(\bar{C})$ & $E_{\mathrm{c}}(T)$ & $E_{\mathrm{m}}(T)$ & $1.25 \cdot 10^{5}$ & - & {$[11,23,29,31,33]$} \\
$E_{\mathrm{T}}(\mathrm{MPa})$ & $E_{\mathrm{T}, \mathrm{f}}(\bar{C})$ & $E_{\mathrm{c}}(T)$ & $E_{\mathrm{m}}(T)$ & $1.25 \cdot 10^{5}$ & - & {$[11,23,29-31,33]$} \\
$\alpha_{\mathrm{L}}(1 / \mathrm{K})$ & $-0.54 \cdot 10^{-6}$ & $2 \cdot 10^{-5}$ & $2 \cdot 10^{-5}$ & $1 \cdot 10^{-5}$ & 0 & {$[32]$} \\
$\alpha_{\mathrm{T}}(1 / \mathrm{K})$ & $1 \cdot 10^{-5}$ & $2 \cdot 10^{-5}$ & $2 \cdot 10^{-5}$ & $1 \cdot 10^{-5}$ & 0 & {$[32]$} \\
$\beta_{\mathrm{L}}(1 / \bar{C})$ & $0.63 \cdot 10^{-2}$ & 0 & 0 & $1.64 \cdot 10^{-2}$ & 0 & {$[27,33]$} \\
$\beta_{\mathrm{T}}(1 / \bar{C})$ & $3.2 \cdot 10^{-2}$ & 0 & 0 & $1.64 \cdot 10^{-2}$ & 0 & {$[27,33]$} \\
$s(\mathrm{~S} / \mathrm{cm})$ & $6.9 \cdot 10^{2}$ & $s_{\mathrm{c}}(T)$ & $S_{\mathrm{m}}(T)$ & - & 7 & {$[2,11,23,35]$} \\
$\nu_{\mathrm{LT}} / \nu_{\mathrm{TT}}(-)$ & $0.2 / 0.2$ & $0.38 / 0.38$ & $0.38 / 0.38$ & $0.28 / 0.28$ & - & \\
$\rho\left(\mathrm{g} / \mathrm{cm}{ }^{3}\right)$ & 1.85 & 1.0 & 1.0 & 3.6 & 1.8 & \\
$c_{p}(\mathrm{~J} / \mathrm{gK})$ & 0.71 & 1.67 & 1.67 & 0.45 & 0.71 & \\
$D_{\mathrm{f}}\left(\mathrm{m}^{2} / \mathrm{s}\right)$ & $6.8 \cdot 10^{-13}$ & - & - & - & - & {$[36]$} \\
\hline
\end{tabular}




\section{Nomenclature}

$V \quad$ Volume fraction of constituent

$V_{\mathrm{p}}^{*} \quad$ Volume fraction of $\mathrm{LiFePO}_{4}$ particles in matrix

$\delta \quad$ Thickness

$L_{\text {lam }} \quad$ Length of lamina

$w_{\text {lam }}$ Width of lamina

$r \quad$ Radius

C Lithium concentration

$\bar{C} \quad$ Normalized lithium concentration

$T$ Temperature

$C_{\text {rate }}$ C-rate

E Elastic modulus

$v \quad$ Poisson's ratio

$\alpha \quad$ Coefficient of thermal expansion

$\beta \quad$ Expansion coefficient due to change in lithium concentration

$s \quad$ Ion/electrical conductivity

$D_{\mathrm{f}} \quad$ Diffusion coefficient of the fibre

$\Gamma \quad$ Electrochemical capacity

$N \quad$ Number of concentric cylinders

$u_{r} \quad$ Radial displacement

$A_{1}, A_{2}$ Constants determined by solving for displacement and stress continuity

$\bar{Q} \quad$ Stiffness matrix

$\varepsilon_{10} \quad$ Strain in fibre direction

$\eta \quad$ Expansion term

$K \quad$ Bulk modulus

$\sigma \quad$ Stress

$i \quad$ Current density

I Current

F $\quad$ Faraday's constant (96487 C/eq)

$J_{n} \quad n$-th order Bessel's function of the first kind

$\lambda_{n} \quad n$-th root of the Bessel's function

$m \quad$ Mass

$Q \quad$ Heat generation

$q_{\text {ext }} \quad$ Heat exchange with surrounding

$R \quad$ Resistance

$\rho \quad$ Density

$c_{p} \quad$ Specific heat

$n_{\mathrm{f}} \quad$ Number of fibres in the lamina

$n_{\text {step }} \quad$ Number of time steps

$t \quad$ Time

$t_{c} \quad$ Time for charge/discharge 